\title{
Association of positive fluid balance and cardiovascular complications after thoracotomy for noncancer lesions
}

This article was published in the following Dove Press journal:

Risk Management and Healthcare Policy

3 July 2014

Number of times this article has been viewed

\author{
Tanyong Pipanmekaporn ${ }^{1,2}$ \\ Yodying Punjasawadwong ${ }^{2}$ \\ Somrat Charuluxananan ${ }^{3}$ \\ Worawut Lapisatepun ${ }^{2}$ \\ Pavena Bunburaphong ${ }^{3}$ \\ Somchareon Saeteng ${ }^{4}$ \\ 'Clinical Epidemiology Program, \\ ${ }^{2}$ Department of Anesthesiology, \\ Faculty of Medicine, Chiang Mai \\ University, Chiang Mai, Thailand; \\ ${ }^{3}$ Department of Anesthesiology, \\ Faculty of Medicine, Chulalongkorn \\ University, Bangkok, Thailand; \\ ${ }^{4}$ Department of Surgery, Faculty of \\ Medicine, Chiang Mai University, \\ Chiang Mai, Thailand
}

Objective: The purpose of this study was to explore the influence of positive fluid balance on cardiovascular complications after thoracotomy for noncancer lesions.

Methods: After approval from an institutional review board, a retrospective cohort study was conducted. All consecutive patients undergoing thoracotomy between January 1, 2005 and December 31, 2011 in a single medical center were recruited. The primary outcome of the study was the incidence of cardiovascular complications, which were defined as cardiac arrhythmia, cardiac arrest, heart failure, myocardial ischemia, and pulmonary embolism. Univariable and multivariable risk regression analyses were used to evaluate the association between positive fluid balance and cardiovascular complications.

Results: A total of 720 patients were included in this study. The incidence of cardiovascular complications after thoracotomy for noncancer lesions was $6.7 \%$ (48 of 720 ). Patients with positive fluid balance $>2,000 \mathrm{~mL}$ had a significantly higher incidence of cardiovascular complications than those with positive fluid balance $\leq 2,000 \mathrm{~mL}$ ( $22.2 \%$ versus $7.0 \%, P=0.005)$. Cardiac arrhythmias were the most common complication. Univariable risk regression showed that positive fluid balance $>2,000 \mathrm{~mL}$ was a significant risk factor (risk ratio $=3.15,95 \%$ confident interval $[\mathrm{CI}]=1.44-6.90, P$-value $=0.004)$. After adjustment for all potential confounding variables during multivariable risk regression analysis, positive fluid balance $>2,000 \mathrm{~mL}$ remained a strong risk factor for cardiovascular complications (risk ratio $=2.18,95 \% \mathrm{CI}=1.36-3.51$, $P$-value $=0.001)$. Causes of positive fluid balance $>2,000 \mathrm{~mL}$ included excessive hemorrhage (48\%), hypotension without excessive hemorrhage (29.6\%), and liberal fluid administration $(22.4 \%)$.

Conclusion: Positive fluid balance was a significant risk factor for cardiovascular complications. Strategies to minimize positive fluid balance during surgery for patients at high risk of cardiovascular complications include preparing adequate blood and blood products, considering appropriate hemoglobin level as a transfusion trigger, and adjusting the optimal dose of local anesthetic for intraoperative thoracic epidural analgesia.

Keywords: cardiac arrhythmias, cardiac arrest, heart failure, myocardial ischemia, hemorrhage

\section{Introduction}

The incidence of cardiovascular complications after thoracic surgery varies among studies, and cardiovascular complications occur in 7\%-30\% of thoracic patients following surgery. ${ }^{1-5}$ These complications not only increase medical costs and prolong hospital stays but also increase the risk of perioperative morbidity and mortality. ${ }^{6,7}$ Most studies of postoperative cardiovascular complications have been done in lung cancer patients, while a large series of patients with noncancer lesions has not been investigated. Thoracic surgery for noncancer lesions is common in most developing countries.
Correspondence: Yodying Punjasawadwong Department of Anesthesiology, Faculty of Medicine, Chiang Mai University, Chiang Mai, Thailand Tel +6653945 522

Fax +6653945526

Email typunja@gmail.com 
There are differences in the pathophysiology of the disease, patient conditions, and risks of surgery between thoracic patients with cancer and noncancer lesions. Previous studies have shown an association between the amount of perioperative fluid administration and perioperative morbidity and mortality after thoracic surgery. ${ }^{1,3,8-10}$ Perioperative positive fluid balance (PFB) significantly increases the risk of postoperative pulmonary complications after thoracic surgery; ${ }^{10,11}$ however, the influence of this factor on postoperative cardiovascular complications has not been clearly demonstrated. ${ }^{10,11}$ Our previous study showed that perioperative PFB $>2,000 \mathrm{~mL}$ was one of the significant risk factors for cardiovascular complications after thoracic surgery. ${ }^{12}$ The purpose of this study was to explore the influence of PFB on cardiovascular complications after thoracotomy for noncancer lesions.

\section{Materials and methods}

The present study was approved by the Institutional Review Board at the Faculty of Medicine, Chiang Mai University. Prospectively collected data for adult patients undergoing noncardiac thoracic surgery for noncancer lesions from January 1 , 2005 through December 31, 2011 in a tertiary medical center were included. Patients 18 years of age and older who had undergone thoracotomy were included. If patients had had more than one thoracic operation, only the cardiovascular events occurring during the first operation were included. Patients having thoracic injury and patients undergoing thoracic spine surgery were excluded from the study.

Noncancer lesions included the following benign intrathoracic diseases: hamartoma, bronchogenic cyst, pulmonary sequestration, bullous disease, bronchiectasis, lung abscess, aspergilloma, and empyema thoracis.

The primary outcome was the incidence of cardiovascular complications after thoracotomy. Cardiovascular complications included cardiac arrhythmias, pulmonary embolism, myocardial infarction, cardiac arrest, and congestive heart failure. Arrhythmias were defined as new onset of postoperative arrhythmias confirmed by 12-lead electrocardiography. Pulmonary embolism was diagnosed according to clinical manifestations including hypoxemia, cardiovascular collapse, or death. Pulmonary embolism was confirmed by computed tomography angiography or a ventilation/perfusion radioisotope scan. ${ }^{3}$ Myocardial infarction was defined as a new Q wave on the electrocardiogram, a positive stress test, evidence of coronary artery stenosis as indicated by the coronary angiogram, or an increase in either the serum creatine kinase MB or troponin I level. ${ }^{13}$ Cardiac arrest was defined as an event requiring cardiopulmonary resuscitation including closed chest cardiac compression. Heart failure was diagnosed by signs or symptoms of pulmonary congestion (shortness of breath), signs of right or left heart failure (cardiomegaly, jugular venous distension, and peripheral edema), and abnormal changes of chest radiography. ${ }^{13}$

All electronic medical records, anesthetic records, and daily medical progress notes recorded by attending anesthesiologists, surgeons, and nurses of all eligible patients were reviewed independently by two peer reviewers. Any disagreement was further discussed to achieve a consensus. Details of pre-anesthetic conditions, anesthetic management, intraoperative events, and perioperative complications during hospitalization of all thoracic patients were extracted. Demographic data included age, sex, body mass index, American Society of Anesthesiologists classification, preexisting coronary artery disease, and other comorbidities. Operative details included type of operation, type of operative approach, side of operation, type(s) of noncancer lesion(s), and duration of surgery. Anesthetic details included presence of central venous pressure monitoring, intraoperative hypotension, the use of vasopressor drugs (including ephedrine, dopamine, epinephrine, and norepinephrine), amount of blood loss, type of blood transfusion (packed red cell, fresh frozen plasma, or platelets), amount of fluid, blood and blood products administration, and PFB ([amount of crystalloids + colloids + packed red cell + plasma + platelets $]-$ [blood loss + urine output $]$ ) during the operation and within the first 2 hours in the postanesthesia care unit or intensive care unit. Patients with PFB were further categorized into PFB $>2,000 \mathrm{~mL}$ and $\leq 2,000 \mathrm{~mL}$. Intraoperative hypotension was defined as systolic blood pressure $<80 \mathrm{mmHg}$ or mean arterial pressure $<60 \mathrm{mmHg}$ for more than 15 minutes. ${ }^{14}$ Excessive hemorrhage was defined as blood loss $>1,000 \mathrm{~mL}$.

\section{Data collection and analysis}

All relevant data were extracted and recorded twice and analyzed using Stata software (version 11.0; StataCorp LP, College Station, TX, USA). Demographic data between patients with and without cardiovascular complications were described and compared using the appropriate statistical tests. Categorical data were presented as number and percent, and continuous data were presented as mean and standard deviation or median and interquartile range where appropriate. Categorical variables were analyzed using Fisher's exact test. Unpaired $t$-test or Wilcoxon rank sum test was used to compare continuous data depending on their distribution. Multivariable binary regression was used to evaluate the association between positive fluid balance and postoperative cardiovascular complications 
controlling for other potential confounding factors. ${ }^{15}$ The criterion for choosing covariates to be included in the model for multivariable analysis was a $P$-value $<0.2$ according to univariable risk regression analysis (infection versus noninfection, parenchymal versus nonparenchymal resection, duration of surgery $>180$ versus $\leq 180$ minutes, intraoperative hypotension, $\mathrm{PFB}>2,000 \mathrm{~mL}$ versus $\leq 2,000 \mathrm{~mL}$ ) and/or any covariates influencing both PFB and cardiovascular complications (advanced age, diabetes mellitus, coronary heart disease). A $P$-value $<0.05$ was considered statistically significant. Cut-off points of the independent variables such as age $(\leq 55$ versus $>55$ years), duration of surgery ( $\leq 180$ minutes versus $>180$ minutes) and PFB ( $\leq 2,000$ versus $>2,000 \mathrm{~mL}$ ) were estimated by the method of maximum likelihood in order to achieve the best discrimination between patients with and without cardiovascular complications. ${ }^{15}$ Assuming a baseline frequency of cardiovascular complications of $6 \%$ in unexposed patients, the estimated sample size required to detect a relative risk of 3 for cardiovascular complications after thoracotomy with exposure to $\mathrm{PFB}>2,000 \mathrm{~mL}$ was 155 patients with an accepted $\alpha$ error of $5 \%$ and a power of $90 \%$.

\section{Results}

A total of 720 patients were included over the seven years of the study period. The overall incidence of cardiovascular complications after thoracotomy was $6.7 \%$ (48 of 720 ). Eight patients experienced more than one cardiovascular complication $(1.1 \%)$. The present study found that there was no significant difference of amount of total fluid administration between thoracic patients with and without cardiovascular complications after thoracotomy $(1,375 \mathrm{ml}$ [600-2,135] versus 1,100 $\mathrm{ml}[650-1,800], P=0.151)$, whereas patients experiencing cardiovascular complications had a significantly higher degree of PFB than those without cardiovascular complications ([907.5 $\mathrm{ml}\{325-1,425\}$ versus $640 \mathrm{ml}\{250-1,110\}, P=0.035])$. The incidence of cardiovascular complications in patients with negative fluid balance, $\mathrm{PFB} \leq 2,000 \mathrm{~mL}$, and PFB $>2,000$ was $9.1 \%$, ( 1 of 11 ), $7.0 \%$ (31 of 440 ), and $22.2 \%$ ( 6 of 27 ), respectively. The incidence of cardiovascular complications in patients with $\mathrm{PFB}>2,000 \mathrm{~mL}$ was significantly higher than the incidence among patients with $\mathrm{PFB} \leq 2,000 \mathrm{~mL}$ $(P=0.005)$. Patients with PFB $>2,000 \mathrm{~mL}$ had a higher intensive care unit admission rate than those with $\mathrm{PFB} \leq 2,000 \mathrm{~mL}$ (59.0\% versus $19.3 \%, P<0.001$ ), whereas the median (IQR) length of hospital stay between groups was not significantly different ( 9 [6-13] versus 8 [5-13] days, $P=0.645)$. Cardiac arrhythmias were the most common cardiovascular complication. The incidence of cardiac arrhythmias in patients with
PFB $>2,000 \mathrm{~mL}$ was significantly higher than the incidence in those with $\mathrm{PFB} \leq 2,000 \mathrm{~mL}(14.8 \%$ versus $4.1 \%, P=0.011)$. Cardiac arrhythmias included atrial fibrillation (AF) (18 of 24, $76 \%$ ), premature ventricular contraction (4 of $24,16 \%$ ), and bradycardia ( 2 of $24,8 \%$ ). Baseline characteristics, operative data, and anesthetic details classified by PFB are presented in Table 1. Frequencies of parenchymal resection, duration of surgery $>180$ minutes, and intraoperative hypotension among patients with $\mathrm{PFB}>2,000 \mathrm{~mL}$ were significantly higher than among those with $\mathrm{PFB} \leq 2,000 \mathrm{~mL}$. Eight of 27 patients $(30 \%)$ with $\mathrm{PFB}>2,000 \mathrm{~mL}$ had had central venous pressure monitoring during the intraoperative period.

The results of the univariable risk regression showed that age $>55$ years, diabetes mellitus, coronary heart disease, infectious lesions, duration of surgery $>180$ minutes, intraoperative hypotension, and PFB $>2,000 \mathrm{~mL}$ increased postoperative cardiovascular complications in patients with noncancer lesions (Table 2). After adjustment for all potential confounders in the multivariable analysis, the results showed that $\mathrm{PFB}>2,000 \mathrm{~mL}$ was an independent risk factor (risk ratio $=2.18 ; 95 \%$ confidence interval, $1.36-3.51 ; P=0.001$ ) (Table 3).

Patients with PFB $>2,000 \mathrm{~mL}$ received significantly higher volumes of crystalloid, colloids, packed red cells, fresh frozen plasma, and platelets than those with $\mathrm{PFB} \leq 2,000 \mathrm{~mL}$. These patients also had a higher incidence of intraoperative blood loss $>1,000 \mathrm{~mL}$ than patients with $\mathrm{PFB} \leq 2,000 \mathrm{~mL}$ (Table 4). Among patients with PFB $>2,000 \mathrm{~mL}$, six patients $(22.3 \%)$ and 11 patients $(40.7 \%)$ had intraoperative blood loss of 500-1,000 mL and $>1,000 \mathrm{~mL}$, respectively. Causes of PFB $>2,000 \mathrm{~mL}$ were excessive hemorrhage (13 of $27,48 \%$ ), hypotension without excessive hemorrhage ( 8 of $27,29.6 \%$ ), and liberal fluid administration (6 of 27, 22.4\%) (Table 5). Eighteen percent ( 5 of 27) of patients with PFB $>2,000 \mathrm{~mL}$ developed intraoperative hypotension and required vasopressors during the intraoperative period to maintain blood pressure.

\section{Discussion}

Several studies have hypothesized that there is an association between the amount of fluid administration and cardiovascular complications after pulmonary resection. ${ }^{1,3,8-10}$ However, only the study by Patel et $\mathrm{al}^{8}$ concluded that an administration of perioperative fluid $>3,000 \mathrm{~mL}$ during the first 24 hours after pneumonectomy increased the incidence of AF. Previous studies have also demonstrated the relationship between PFB and cardiovascular complications after cardiothoracic surgery. ${ }^{11,16}$ Wei et al concluded 
Table I Patient characteristics and operative and anesthetic data

\begin{tabular}{|c|c|c|c|}
\hline Parameters & $\begin{array}{l}\text { Positive fluid balance } \\
>2,000 \mathrm{~mL}(\mathrm{n}=27)\end{array}$ & $\begin{array}{l}\text { Positive fluid balance } \\
\leq 2,000 \mathrm{~mL}(\mathrm{n}=44 \mathrm{I})\end{array}$ & $P$-value \\
\hline \multicolumn{4}{|l|}{ Demographic data } \\
\hline Age (years), mean $\pm S D$ & $49.5 \pm 13.9$ & $51.5 \pm 16.2$ & 0.538 \\
\hline$\leq 55, \mathrm{n}(\%)$ & $17(63.0 \%)$ & $25 \mathrm{I}(57.0 \%)$ & \\
\hline$>55, \mathrm{n}(\%)$ & $10(37.0 \%)$ & $190(43.0 \%)$ & \\
\hline Sex, n (\%) & & & 0.419 \\
\hline Female & $5(18.5 \%)$ & $112(25.6 \%)$ & \\
\hline Male & $22(81.5 \%)$ & $328(74.4 \%)$ & \\
\hline Body mass index $\left(\mathrm{kg} / \mathrm{m}^{2}\right)$, mean $\pm S D$ & $19.4 \pm 3.4$ & $20.5 \pm 3.7$ & 0.275 \\
\hline ASA classification, $n, \%$ & & & 0.783 \\
\hline 1 & $2(7.4 \%)$ & 49 (11.1\%) & \\
\hline 2 & $15(55.6 \%)$ & $249(56.5 \%)$ & \\
\hline 3 & $10(37.0 \%)$ & $143(32.4 \%)$ & \\
\hline \multicolumn{4}{|l|}{ Comorbidity } \\
\hline Hypertension, n, \% & & & 0.089 \\
\hline No & $25(92.6 \%)$ & $348(79.0 \%)$ & \\
\hline Yes & $2(7.4 \%)$ & $92(21.0 \%)$ & \\
\hline Diabetes mellitus, $n, \%$ & & & 0.340 \\
\hline No & $25(92.6 \%)$ & $380(86.2 \%)$ & \\
\hline Yes & $2(7.4 \%)$ & $6 \mathrm{I}(13.8 \%)$ & \\
\hline Renal disease, n, \% & & & 0.468 \\
\hline No & $25(92.6 \%)$ & 387 (88.0\%) & \\
\hline Yes & $2(7.4 \%)$ & $53(12.0 \%)$ & \\
\hline Coronary artery disease, $n, \%$ & & & 0.566 \\
\hline No & $26(96.3 \%)$ & $429(98.0 \%)$ & \\
\hline Yes & I (3.7\%) & $9(2.0 \%)$ & \\
\hline Preoperative hemoglobin $(g / d L)$, mean $\pm S D$ & $11.1 \pm 2.0$ & $11.5 \pm 2.0$ & 0.346 \\
\hline \multicolumn{4}{|l|}{ Operative details } \\
\hline Surgical conditions, $\mathrm{n}, \%$ & & & 0.640 \\
\hline Elective surgery & $12(44.4 \%)$ & $217(49.2 \%)$ & \\
\hline Emergency surgery & $15(55.6 \%)$ & $223(50.8 \%)$ & \\
\hline Type of lesions, $n, \%$ & & & 0.807 \\
\hline Non-infection & $6(22.2 \%)$ & $107(24.3 \%)$ & \\
\hline Infection & 21 (77.8\%) & $324(75.7 \%)$ & \\
\hline Type of operations, n, \% & & & $<0.001$ \\
\hline Parenchymal resection & II (40.7\%) & $110(25.0 \%)$ & \\
\hline Nonparenchymal resection & $16(59.3 \%)$ & 331 (75.0\%) & \\
\hline Duration of surgery (min), mean $\pm S D$ & $216.7 \pm 80.5$ & $|3| .0 \pm 6 \mid .7$ & $<0.00$ I \\
\hline$\leq 180, n, \%$ & $9(34.6 \%)$ & $362(82.0 \%)$ & \\
\hline$>180, n, \%$ & $17(65.4 \%)$ & $79(18.0 \%)$ & \\
\hline Intraoperative hypotension, $\mathrm{n}, \%$ & & & $<0.001$ \\
\hline No & 20 (74.0\%) & 419 (95.0\%) & \\
\hline Yes & $7(16.0 \%)$ & $22(5.0 \%)$ & \\
\hline
\end{tabular}

Abbreviations: ASA, American Society of Anesthesiologists classification; min, minutes; SD, standard deviation.

that an average cumulative PFB of $2,750 \pm 1,361 \mathrm{~mL}$ on postoperative day 2 after esophageal surgery increased the incidence of cardiac arrhythmias and heart failure. ${ }^{11}$ Kalus et al found that patients with AF had a significantly greater amount of net fluid balance on postoperative day 2 after cardiothoracic surgery than those without AF $(52 \pm 1,032 \mathrm{~mL}$ versus $-408 \pm 1,081 \mathrm{~mL}) .{ }^{16}$ However, Møller et al reported that PFB $>4,000 \mathrm{~mL}$ during anesthesia following pneumonectomy did not increase the risk of cardiac arrhythmias. ${ }^{10}$
The association of fluid and cardiovascular complications among studies focused on two main aspects: total amount of fluid administration and degree of PFB. Timing of the assessment of cardiovascular complications differed among studies, conducted, for example, during anesthesia or at 24 or 48 hours after the surgery. No current evidence supports whether the amount of fluid or PFB is the more important factor. However, results of most studies have shown that a higher amount of fluid intake or higher PFB accompanies 
Table 2 Univariable risk regression of postoperative cardiovascular complications

\begin{tabular}{|c|c|c|c|}
\hline Parameters & Risk ratio & $95 \% \mathrm{Cl}$ & $P$-value \\
\hline \multicolumn{4}{|l|}{ Demographic data } \\
\hline Age $>55$ versus $\leq 55$ years & 3.15 & $1.68-5.88$ & $<0.001$ \\
\hline \multicolumn{4}{|l|}{ Comorbidity } \\
\hline Hypertension & 1.67 & $0.90-3.08$ & 0.101 \\
\hline Diabetes mellitus & 1.86 & $0.94-3.69$ & 0.077 \\
\hline Renal diseases & 1.79 & $0.87-3.67$ & 0.112 \\
\hline Coronary artery disease & 6.45 & $3.14-13.22$ & $<0.001$ \\
\hline Infection versus noninfection & 1.13 & $0.55-2.31$ & 0.733 \\
\hline \multicolumn{4}{|l|}{ Operative details } \\
\hline \multicolumn{4}{|l|}{ Type of operation } \\
\hline $\begin{array}{l}\text { Parenchymal resection versus } \\
\text { nonparenchymal resection }\end{array}$ & 1.32 & $0.7 I-2.45$ & 0.375 \\
\hline $\begin{array}{l}\text { Duration of surgery }>180 \\
\text { versus } \leq 180 \text { minutes }\end{array}$ & 2.62 & $1.44-4.75$ & 0.002 \\
\hline \multicolumn{4}{|l|}{ Anesthetic details } \\
\hline Intraoperative hypotension & 3.50 & $1.77-6.93$ & $<0.001$ \\
\hline $\begin{array}{l}\text { Positive fluid balance }>2,000 \\
\text { versus } \leq 2,000 \mathrm{~mL}\end{array}$ & 3.15 & $1.44-6.90$ & 0.004 \\
\hline
\end{tabular}

Abbreviation: $\mathrm{Cl}$, confidence interval.

a higher incidence of postoperative cardiovascular complications. The present study found that PFB was superior to the total amount of fluid intake as a risk factor for postoperative cardiovascular complications because it reflected the balance between fluid intake and output of an individual patient. This study also demonstrated that PFB $>2,000 \mathrm{~mL}$ was an independent risk factor for cardiovascular complications, with a risk ratio of 2.2.

The current study found that $85 \%$ (23 of 27 ) of patients with $\mathrm{PFB}>2,000 \mathrm{~mL}$ received a relatively large amount of

Table 3 Multivariable risk regression of postoperative cardiovascular complications

\begin{tabular}{|c|c|c|c|}
\hline Parameters & Risk ratio & $95 \% \mathrm{Cl}$ & $P$-value \\
\hline \multicolumn{4}{|l|}{ Demographic data } \\
\hline Age $>55$ versus $\leq 55$ years & 3.41 & $1.94-5.98$ & $<0.001$ \\
\hline \multicolumn{4}{|l|}{ Co-morbidity } \\
\hline Hypertension & 0.74 & $0.37-1.49$ & 0.402 \\
\hline Diabetes mellitus & 2.36 & $1.41-3.96$ & 0.001 \\
\hline Renal diseases & 1.13 & $0.56-2.30$ & 0.727 \\
\hline Coronary artery disease & 4.62 & $2.22-9.59$ & $<0.001$ \\
\hline \multicolumn{4}{|l|}{ Operative details } \\
\hline $\begin{array}{l}\text { Duration of surgery }>180 \\
\text { versus } \leq 180 \text { minutes }\end{array}$ & 2.42 & $1.21-4.85$ & 0.012 \\
\hline $\begin{array}{l}\text { Parenchymal versus non- } \\
\text { parenchymal resection }\end{array}$ & 1.19 & $0.60-2.37$ & 0.615 \\
\hline \multicolumn{4}{|l|}{ Anesthetic details } \\
\hline Intraoperative hypotension & 3.11 & I.79-5.42 & $<0.001$ \\
\hline $\begin{array}{l}\text { Positive fluid balance }>2,000 \\
\text { versus } \leq 2,000 \mathrm{~mL}\end{array}$ & 2.18 & $|.36-3.5|$ & 0.001 \\
\hline
\end{tabular}

Abbreviation: $\mathrm{Cl}$, confidence interval. perioperative fluid replacement, which ranged between 3,000 and $9,800 \mathrm{~mL}$ over a short period during anesthesia (average 4 hours), and $22 \%$ of these patients developed postoperative cardiovascular complications. According to Starling 's myocardial performance curve, an increase in cardiac filling pressure by fluid loading can increase myocardial function and cardiac output. However, if left ventricular end-diastolic volume increases beyond particular points, this could depress myocardial function, decrease cardiac output, and increase postoperative cardiac morbidity. ${ }^{17}$ In animal studies, excessive fluid administration could increase intravascular volume and subsequently atrial pressure as well as increase the incidence of $\mathrm{AF}^{18,19}$ In addition, releasing atrial stretch could completely reverse the AF. ${ }^{18-20}$ Although several other risk factors for cardiac arrhythmias after thoracic surgery have been described, PFB is frequently encountered. Avoidance of excessive fluid administration could help to minimize the occurrence of cardiac arrhythmias.

Previous studies have shown that several comorbidities such as hypertension, diabetes mellitus, coronary artery disease, pulmonary disease, and renal impairment increased the incidence of perioperative cardiac morbidity and mortality. ${ }^{21}$ Hypertension in patients is often associated with left ventricular hypertrophy. Such patients are prone to develop intraoperative hypotension and have an increased risk of myocardial ischemia. ${ }^{22}$ Our previous study demonstrated that diabetes mellitus and coronary artery disease were significant independent risk factors for cardiovascular complications after thoracic surgery. ${ }^{12}$ In addition, patients with diabetes mellitus and coronary artery disease are at increased risk of myocardial ischemia, congestive heart failure, or death after noncardiac surgery. ${ }^{21,23,24}$ The use of functional hemodynamic monitoring as well as invasive hemodynamic monitoring (such as central venous pressure, pulmonary artery catheters, or transesophageal echocardiography) are recommended, particularly in high risk patients. ${ }^{21,22}$ These devices are helpful in estimating volume status and optimizing fluid administration; hence, unnecessary and harmful PFB could be avoided. Furthermore, a surgical intensive care unit or high dependency ward should be provided for improving postoperative medical surveillance.

Several studies proposed that thoracic surgery for chronic infection was a risk for massive hemorrhage..$^{25,26}$ Chronic inflammation and infection can promote severe pleural adhesions, adhesions around major vessels, or hypervascularization. ${ }^{25,26}$ Sometimes, surgery in these conditions is difficult to perform, consumes a long operation time, causes extensive blood loss, and increases the 
Table 4 Amount of fluid intake and blood components classified by positive fluid balance

\begin{tabular}{|c|c|c|c|}
\hline Fluid intake and output & $\begin{array}{l}\text { Positive fluid balance } \\
>2,000 \mathrm{~mL}(\mathrm{n}=27)\end{array}$ & $\begin{array}{l}\text { Positive fluid balance } \\
\leq 2,000 \mathrm{~mL}(\mathrm{n}=544)\end{array}$ & $P$-value \\
\hline Total fluid intake $(\mathrm{mL}), \mathrm{mdn}$ (IQR) & $4,280(3,500-5,000)$ & I,I $50(650-1,800)$ & $<0.00$ I \\
\hline Crystalloid & $3,000(2,200-3,350)$ & $900(580-1,350)$ & $<0.001$ \\
\hline Colloids & $1,000(0-1,700)$ & 0 & $<0.001$ \\
\hline Packed red blood cell $(\mathrm{mL})$ & $530(0-800)$ & 0 & $<0.001$ \\
\hline 0 units, $\mathrm{n}(\%)$ & $10(37.0 \%)$ & 459 (84.3\%) & \\
\hline $\mathrm{I}-3$ units, $\mathrm{n}(\%)$ & $12(44.4 \%)$ & 81 (I5.0\%) & \\
\hline$>3$ units, $n(\%)$ & $5(18.6 \%)$ & $4(0.7 \%)$ & \\
\hline Fresh frozen plasma $(\mathrm{mL}) \mathrm{mdn}(\mathrm{IQR})$ & $0(0-190)$ & 0 & $<0.001$ \\
\hline 0 units & $20(74.0 \%)$ & $523(96.0 \%)$ & \\
\hline$I-3$ units & $3(11.0 \%)$ & $14(2.7 \%)$ & \\
\hline$>3$ units & $4(15.0 \%)$ & $7(1.3 \%)$ & \\
\hline Platelets (mL), mdn (IQR) & $280(200-360)$ & 0 & $<0.001$ \\
\hline 0 units, $\mathrm{n}(\%)$ & $25(92.6 \%)$ & $544(100.0 \%)$ & $<0.001$ \\
\hline $\mathrm{I}-3$ units, $\mathrm{n}(\%)$ & 0 & 0 & \\
\hline$>3$ units, $\mathrm{n}(\%)$ & $2(7.4 \%)$ & 0 & \\
\hline Intraoperative blood loss (mL), mdn (IQR) & $800(400-1,500)$ & $200(100-300)$ & $<0.001$ \\
\hline$<500, \mathrm{n}(\%)$ & $10(37.0 \%)$ & $452(83.0 \%)$ & \\
\hline $500-1,000, \mathrm{n}(\%)$ & $6(22.3 \%)$ & $76(14.0 \%)$ & \\
\hline$>1,000, \mathrm{n}(\%)$ & II (40.7\%) & $16(3.0 \%)$ & \\
\hline Urine output (mL), mdn (IQR) & $420(180-900)$ & $200(100-375)$ & 0.001 \\
\hline
\end{tabular}

Abbreviations: mdn, median; IQR, interquartile range.

opportunity for blood transfusion. ${ }^{4}$ The results of our study showed that the most common cause of PFB $>2,000 \mathrm{~mL}$ was related to excessive hemorrhage during surgery. After careful review, the authors found that in cases of excessive hemorrhage, two main contributing factors for patients receiving $\mathrm{PFB}>2,000 \mathrm{~mL}$ were delayed blood transfusion and inadequate preparation of blood and blood products. The causes of delayed blood transfusion were inappropriate preoperative blood preparation and inappropriate criteria for transfusion triggers before starting blood transfusion. According to our hospital practices, preoperative blood typing and screening are implemented for most scheduled surgical procedures to reduce the cost of unnecessary full crossmatched blood. Therefore, patients could not receive blood transfusion promptly at the time of unexpected excessive hemorrhage. Large amounts of crystalloid and colloid solutions were used initially for fluid resuscitation and to maintain hemodynamic stability. In addition, crystalloid solution was administered in a volume triple that of any blood loss. Furthermore, inadequate blood and

Table 5 Causes of positive fluid balance

\begin{tabular}{ll}
\hline Causes & $\mathbf{n ~ ( \% )}$ \\
\hline Excessive hemorrhage & $13(48.0 \%)$ \\
Hypotension without evidence of significant hemorrhage & $8(29.6 \%)$ \\
Liberal fluid administration & $6(22.4 \%)$ \\
\hline
\end{tabular}

blood product preparation was due to underestimating the blood loss for specific types of surgery. The findings of this study should increase awareness of surgical team personnel regarding blood and blood product preparation. An adequate amount of fully crossmatched blood and blood products should be prepared preoperatively in surgery for chronic infection such as empyema thoracis, aspergilloma, and tuberculosis. Furthermore, the optimal hemoglobin transfusion trigger for individual patients should be discussed preoperatively, particularly in the case of elderly patients and patients with poor cardiac or pulmonary reserve. Although the main indication of intraoperative blood transfusion is excessive blood loss, transfusion is also given for other reasons. Blood transfusion is given to improve oxygen delivery in patients with preoperative anemia and correct coagulation defects. In addition, blood and blood products are sometimes given inappropriately due to an overestimated intraoperative blood loss. The indications for perioperative blood transfusion should be based on several criteria such as signs of inadequate tissue oxygenation, cardiopulmonary reserve, comorbidity, extent of blood loss, and level of intraoperative hemoglobin. ${ }^{27} \mathrm{~A}$ clinical practice guideline for blood transfusions should be hospital policy-based, developed and considered carefully by all medical experts to minimize risks of blood transfusion and medical costs due to inappropriate blood transfusions. For patients with 
cardiovascular risk factors or those having surgery with a high risk of bleeding, the use of intraoperative hemodynamic monitoring is helpful in diagnosing the causes of hypotension, assessing cardiac contractility, or guiding fluid administration. Currently, controversies exist concerning the reliability of static parameters of cardiac preload such as central venous pressure or pulmonary artery occlusion pressure monitoring in fluid management. Previous studies have shown that the use of dynamic parameters of cardiac preload for optimization of intraoperative fluid management could reduce morbidity. ${ }^{28,29}$ In addition, many studies have suggested that dynamic parameters of cardiac preload such as stroke volume variation or pulse pressure variation are more reliable predictors of fluid responsiveness during major surgery than static parameters. ${ }^{28,30}$ Furthermore, Lee et al demonstrated that pulse pressure variation was a good predictor of fluid responsiveness during one-lung ventilation for thoracic surgery. ${ }^{31}$ A randomized controlled trial demonstrated that the use of stroke volume variation monitoring could significantly reduce intraoperative fluid replacement during one-lung ventilation compared with conventional fluid management. ${ }^{29}$ However, more studies are required to demonstrate the advantage of dynamic parameters during open chest conditions and one-lung ventilation.

Hypotension without evidence of excessive hemorrhage was the second most common cause of patients experiencing PFB $>2,000 \mathrm{~mL}$. Two prospective cohort studies concluded that intraoperative hypotension significantly increased the risk of postoperative myocardial ischemia and heart failure. ${ }^{14,32}$ Although thoracic epidural analgesia provides an effective analgesia for thoracic surgery, this technique carries a risk of significant hypotension. The results of our study also showed that intraoperative hypotension occurred in patients receiving thoracic epidural analgesia even in the case of blood loss $<500 \mathrm{~mL}$. Administration of fluid was used to correct various degrees of hypotension. Decision making should be careful in order to outweigh the benefit of thoracic epidural analgesia during introperative period over the incidence of hypotension. The use of thoracic epidural analgesia during intraoperative period should be administered with caution in order to minimize an incidence of hypotension. The effect of central neural blockade due to thoracic epidural analgesia could enhance the intensity of hypotension caused by general anesthesia, particularly in hypovolemic patients or patients with significant hemorrhage. To reduce an excessive amount of fluid administration during thoracotomy, vasopressors should be considered during the perioperative period for maintaining hemodynamic stability, particularly in patients with a high risk of cardiovascular complications. ${ }^{33}$ Intraoperative analgesia could be managed by using intravenous opioids, and thoracic epidural analgesia should be started after surgery. If thoracic epidural analgesia is used during the intraoperative period, the dose of local anesthetic agents should be reduced or adjusted as appropriate.

In our study, we found that excessive fluid administration was another cause of PFB $>2,000 \mathrm{~mL}$. Our institute is also a training center for anesthesiologists, physicians, and nurses. Some possible explanations for excessive fluid administration include trainee lack of knowledge, inexperience, lack of vigilance, inappropriate decisions, and inadequate supervision, as well as emergency conditions and ineffective communication. Suggested corrective strategies include additional training, quality assurance activity, providing clinical practice guidelines for perioperative fluid management, improved supervision, and improvement of communication among surgical personnel.

There were some limitations of this study. First, this study was retrospective; therefore, some information could be missing. Second, we did not focus on types of fluid given, for example, colloid, crystalloid or blood components. These could have had effects on the amount of fluid administration. For example, colloid solutions are retained in the intravascular space longer and maintain oncotic pressure better than crystalloid solutions. This was an observational study, hence, there could be some unknown confounding factors that might affect cardiovascular complications. Randomized controlled trials should be conducted to compare the effect of restrictive versus liberal fluid administration on the incidence of cardiovascular complications after thoracic surgery. Nevertheless, the author realizes that intraoperative fluid management is an anesthetic-related factor and probably a modifiable risk factor. Further study is required to answer this hypothesis. Lastly, this study was conducted in a single center. The experience and practices of an individual surgical team in one center might be different from others. Large multicenter studies are needed in the future to ensure sufficient statistical power to confirm the effect of this potential risk factor on cardiovascular complications.

\section{Conclusion}

We found the incidence of cardiovascular complications after thoracotomy in noncancer lesions to be $6.7 \%$ and that $\mathrm{PFB}>2,000 \mathrm{~mL}$ was an independent risk factor for cardiovascular complications. Proper preoperative blood and blood product preparation and the use of proper 
hemodynamic monitoring should be among the main strategies utilized during anesthetic management of high risk surgery. An adjusted dose of local anesthetic for thoracic epidural analgesia during the intraoperative period should be considered to minimize intraoperative hypotension. In addition, effective corrective strategies to improve trainee performance should be deployed. These include clinical practice guidelines, additional training, and improved supervision.

\section{Author contributions}

Tanyong Pipanmekaporn is familiar with the original study data and reviewed the analysis of the data. Yodying Punjasawadwong and Somrat Charuluxananan helped design the study and analyzed the data. Worawut Lapisatepun helped design the study. Pavena Bunburaphong and Somchareon Saeteng helped design the study and reviewed the analysis of the data. All authors took part in drafting the article or revising it critically for important intellectual content. All authors approved the final manuscript.

\section{Acknowledgments}

The authors would like to thank their surgical and anesthesiology colleagues and the nursing staff for their assistance with the study. The study was financially supported by the Faculty of Medicine Research Fund, Chiang Mai University. The authors would also like to thank Miss Ruth Barnard Leatherman for her assistance with editing the manuscript.

\section{Disclosure}

The authors report no conflicts of interest in this work.

\section{References}

1. Miller DL, Deschamps C, Jenkins GD, Bernard A, Allen MS, Pairoler PC. Completion pneumonectomy: factors affecting operative mortality and cardiopulmonary morbidity. Ann Thorac Surg. 2002;74(3):876-883.

2. Harpole DH Jr, DeCamp MM Jr, Daley J, et al. Prognostic models of thirty-day mortality and morbidity after major pulmonary resection. J Thorac Cardiovasc Surg. 1999;117(5):969-979.

3. Marret E, Miled F, Bazelly B, et al. Risk and protective factors for major complications after pneumonectomy for lung cancer. Interac Cardiovasc Thorac Surg. 2010;10(6):936-939.

4. Hu XF, Duan L, Jiang G, Wang H, Liu HC, Chen C. Risk factors for early postoperative complications after pneumonectomy for benign lung disease. Ann Thorac Surg. 2013;95(6):1899-1904.

5. Owen RM, Force SD, Pickens A, Mansour KA, Miller DL, Fernandez FG. Pneumonectomy for benign disease: analysis of the early and late outcomes. Eur J Cardiothorac Surg. 2013;43(2):312-317.

6. Roselli EE, Murthy SC, Rice TW, et al. Atrial fibrillation complicating lung cancer resection. J Thorac Cardiovasc Surg. 2005;130(2):438-444.

7. Onaitis M, D'Amico T, Zhao Y, O'Brien S, Harpole D. Risk factors for atrial fibrillation after lung cancer surgery: analysis of The Society of Thoracic Surgeons general thoracic surgery database. Ann Thorac Surg. 2010;90(2):368-374.
8. Patel RL, Townsend ER, Fountain SW. Elective pneumonectomy: factors associated with morbidity and operative mortality. Ann Thorac Surg. 1992;54(1):84-88.

9. Bernard A, Deschamps C, Allen MS, et al. Pneumonectomy for malignant disease: factors affecting early morbidity and mortality. J Thorac Cardiovasc Surg. 2001;121(6):1076-1082.

10. Møller AM, Pedersen T, Svendsen PE, Engquist A. Perioperative risk factors in elective pneumonectomy: the impact of excess fluid balance. Eur J Anaesthesiol. 2002;19(1):57-62.

11. Wei S, Tian J, Song X, Chen Y. Association of perioperative fluid balance and adverse surgical outcomes in esophageal cancer and esophagogastric junction cancer. Ann Thorac Surg. 2008;86(1):266-272.

12. Pipanmekaporn T, Punjasawadwong Y, Charuluxananan S, et al. Incidence and risk factors for cardiovascular complications after thoracic surgery for non-cancer lesions. $J$ Cardiothorac Vasc Anesth. 2014;28(4):960-965.

13. Mangano DT, Browner WS, Hollenberg M, London MJ, Tubau JF, Tateo IM. Association of perioperative myocardial ischemia with cardiac morbidity and mortality in men undergoing noncardiac surgery. N Engl J Med. 1990;323(26):1781-1788.

14. Walsh M, Devereaux PJ, Garg AX, et al. Relationship between intraoperative mean arterial pressure and clinical outcomes after noncardiac surgery: toward an empirical definition of hypotension. Anesthesiology. 2013;119(3):507-515.

15. Vittinghoff E, Shiboski SC, Glidden DV, McCulloch CE, editors. Regression Methods in Biostatistics: Linear, Logistic, Survival, and Repeated Measure Models. 1st ed. New York: Springer; 2004.

16. Kalus JS, Caron MF, White CM, et al. Impact of fluid balance on incidence of atrial fibrillation after cardiothoracic surgery. Am J Cardiol. 2004;94(11):1423-1425.

17. Holte K, Sharrock NE, Kehlet H. Pathophysiology and clinical implications of perioperative fluid excess. Br J Anaesth. 2002;89(4): 622-632.

18. Ravelli F, Allessie M. Effects of atrial dilatation on refractory period and vulnerability to atrial fibrillation in the isolated langendorff-perfused rabbit heart. Circulation. 1997;96(5):1686-1695.

19. Sideris DA, Toumanidis ST, Tselepatiotis E, et al. Atrial pressure and experimental atrial fibrillation. Pacing Clin Electrophysiol. 1995; 18(9 pt 1):1679-1685.

20. Brathwaite D, Weissman C. The new onset of atrial arrhythmias following major noncardiothoracic surgery is associated with increased mortality. Chest. 1998;114(2):462-468.

21. Fleisher LA, Beckman JA, Brown KA, et al. ACC/AHA 2007 guidelines on perioperative cardiovascular evaluation and care for noncardiac surgery: a report of the American College of Cardiology/American Heart Association Task Force on Practice Guidelines (Writing Committee to Revise the 2002 Guidelines on Perioperative Cardiovascular Evaluation for Noncardiac Surgery). Circulation. 2007;116(17):e418-e499.

22. Landesberg G, Beattie WS, Mosseri M, Jaffe AS, Alpert JS. Perioperative myocardial infarction. Circulation. 2009;119(22):2936-2944.

23. Virkkunen J, Heikkinen M, Lepäntalo M, Metsänoja R, Salenius J-P. Diabetes as an independent risk factor for early postoperative complications in critical limb ischemia. J Vasc Surg. 2004;40(4): 761-767.

24. Lee TH, Marcantonio ER, Mangione CM, et al. Derivation and prospective validation of a simple index for prediction of cardiac risk of major noncardiac surgery. Circulation. 1999;100(10):1043-1049.

25. Massard G, Dabbagh A, Wihlm JM, et al. Pneumonectomy for chronic infection is a high-risk procedure. Ann Thorac Surg. 1996;62(4): 1033-1038.

26. Reed CE. Pneumonectomy for chronic infection: fraught with danger? Ann Thorac Surg. 1995;59(2):408-411.

27. Practice Guidelines for blood component therapy: A report by the American Society of Anesthesiologists Task Force on Blood Component Therapy. Anesthesiology. 1996;84(3):732-747. 
28. Benes J, Chytra I, Altmann P, et al. Intraoperative fluid optimization using stroke volume variation in high risk surgical patients: results of prospective randomized study. Crit Care. 2010;14(3):R118.

29. Zhang J, Chen CQ, Lei XZ, Feng ZY, Zhu SM. Goal-directed fluid optimization based on stroke volume variation and cardiac index during one-lung ventilation in patients undergoing thoracoscopy lobectomy operations: a pilot study. Clinics (Sao Paulo). 2013;68(7):1065-1070.

30. Preisman S, Kogan S, Berkenstadt H, Perel A. Predicting fluid responsiveness in patients undergoing cardiac surgery: functional haemodynamic parameters including the Respiratory Systolic Variation Test and static preload indicators. Br J Anaesth. 2005;95(6):746-755.
31. Lee JH, Jeon Y, Bahk JH, et al. Pulse pressure variation as a predictor of fluid responsiveness during one-lung ventilation for lung surgery using thoracotomy: randomised controlled study. Eur J Anaesthesiol. 2011;28(1):39-44.

32. Charlson ME, Mackenzie R, Gold JP, et al. The preoperative and intraoperative hemodynamic predictors of postoperative myocardial infarction or ischemia in patients undergoing noncardiac surgery. Ann Surg. 1989;210(5):637-648.

33. Slinger PD, Campos JH. Anesthesia for Thoracic Surgery. In: Miller RD, Eriksson LI, editors. Miller's Anesthesia. Philadelphia: Churchill Livingstone; 2010:1819-1887.

\section{Publish your work in this journal}

Risk Management and Healthcare Policy is an international, peerreviewed, open access journal focusing on all aspects of public health, policy, and preventative measures to promote good health and improve morbidity and mortality in the population. The journal welcomes submitted papers covering original research, basic science, clinical \& epidemio-

\section{Dovepress}

logical studies, reviews and evaluations, guidelines, expert opinion and commentary, case reports and extended reports. The manuscript management system is completely online and includes a very quick and fair peerreview system, which is all easy to use. Visit http://www.dovepress.com/ testimonials.php to read real quotes from published authors.

Submit your manuscript here: http://www.dovepress.com/risk-management-and-healthcare-policy-journal 